\title{
Characterization of Gas and Particle Emission from Smoldering Incenses with Various Diameters
}

\author{
T. T. Yang, ${ }^{1}$ C. C. Chen, ${ }^{2}$ J. M. Lin $^{3}$ \\ ${ }^{1}$ Department of Environmental Engineering and Health, Yuanpei University, Room \\ 407, Number 306, Yuanpei Street, Hsin Chu, Taiwan, Republic of China \\ 2 Institute of Occupational Medicine and Industrial Hygiene, College of Public Health, \\ National Taiwan University, Room 718, 7F, Number 17, Xu-Zhou Road 10020, Taipei, \\ Taiwan, Republic of China \\ ${ }^{3}$ Institute of Environmental Health, College of Public Health, National Taiwan \\ University, Room 739, 7F, Number 17, Xu-Zhou Road 10020, Taipei, Taiwan, \\ Republic of China
}

Received: 10 October 2006/Accepted 13 November 2006

As a common religious ritual in Chinese society, burning incense sticks causes air pollution and is related to the occurrence of lung cancer (MacLennan et al. 1977), childhood leukemia (Lowergard et al. 1987) and brain tumors (Preston-Martin et al. 1982). The Ames test has demonstrated the mutagenic effect of incense smoke (Sato et al. 1980; Rasmussen et al. 1987; Chang et al. 1997).

Incense is burned in a smoldering state, subsequently producing incense smoke that contains gas and particulates. The gas phase consists of carbon monoxide (Jetter et al. 2002), carbon dioxide (Yang and Lin, 2005), nitrogen oxides, formaldehyde, volatile organic compounds (VOCs) and so on. The particulate phase contains almost exclusively of pure particulates (Cheng et al. 1995), but to these particulates may be bound semi-volatile organic compounds (Schoental et al. 1967; Lin and Wang, 1994; Lin and Tang, 1994; Lin and Lee, 1998). The particulates tend to be in the submicron range, and include ultrafine particles with that are smaller than $100 \mathrm{~nm}$. Ultrafine particles that are deposited in human alveoli are likely to increase cellular oxidative stress and inflammatory responses (Dick et al. 2003).

The characteristics of incense smoke may vary with the constituents of the incense stick and the conditions of combustion (airflow, temperature, humidity and oxygen content). This study elucidates how temperature affects the yields of pollutants from smoldering incense.

\section{MATERIALS AND METHODS}

This study focused on a brand of less-smoke incense prepared by a local manufacturer. Incense sticks with diameters of $3,3.75$, and $5 \mathrm{~mm}$ were used. Their ingredients were unknown, but carbon, hydrogen and nitrogen contents were identified using an elemental analyzer (2400 CHN Elemental Analyzer, Perkin-Elmer, U.S.A.). The heat value of each incense was measured using an oxygen bomb calorimeter (1271 Oxygen Bomb Calorimeter, Parr Instrument Company, U.S.A.). 
An incense stick was burned in a combustion system, which has been in detail elsewhere (Yang and Lin, 2005). An incense stick was ignited and burnt at flow rate of $5 \mathrm{~L} / \mathrm{min}$. The surface temperature of the burning tip of incense was measured using a K-type thermocouple made of $79 \mu \mathrm{m}$ nickel-aluminum and nickel-chrome wires. The incense smoke was led into a $7.3 \mathrm{~L}$ test chamber. Particles were counted and their sizes measured using a Scanning Mobility Particle Sizer (SMPS, Model 3936, TSI Inc., USA), which coupled a differential mobility analyzer (DMA, Model 3080, TSI Inc.) with a condensation particle counter (CPC, Model 3022, TSI Inc.). All particles were sampled using a quartz filter ( $37 \mathrm{~mm}$, Pallgelman, U.S.A.) in a two-piece cassette holder at flow rate of 2 $\mathrm{L} / \mathrm{min}$ for ten minutes to determine their concentration. The incense smoke was diluted with pure nitrogen ( $99.99 \%$, Shen Yi Gas Co., Taiwan) before it entered a $1.4 \mathrm{~L}$ dilution chamber to measure the concentrations of carbon monoxide and carbon dioxide. This step fitted the concentration of pollutants into the specified detectable ranges of $0-5000 \mathrm{ppm}$ for $\mathrm{CO}_{2}$ and $0-500 \mathrm{ppm}$ for $\mathrm{CO}$, which were set for the Q-Trak ${ }^{\mathrm{TM}}$ Indoor Air Quality Monitor (Model 8550/8551, TSI Inc., U.S.A.), which measured the $\mathrm{CO}_{2}$ and $\mathrm{CO}$ concentrations with an accuracy of $\pm 3 \%$. The ppbRAE Portable VOC Monitor (RAE SYSTEMS Inc., USA) with UV at $10.6 \mathrm{eV}$ measured a total VOC of $0-200 \mathrm{ppm}$ with an accuracy of $\pm 10 \%$. Zero calibration and span calibration were for each monitoring instrument using a reference compound $\left(\mathrm{CO}_{2}, \mathrm{CO}\right.$ or isobutylene $)$ of known concentration, by following the manufacturer's instructions. Standard isobutylene (10 ppm, RAE SYSTEMS Inc., USA) was adopted to calibrate the VOC Monitor. Before and after burning, an individual joss stick was weighed and so that the net loss of mass and the rate of burning of incense could be determined.

The emission rates and emission factors of particles (or gaseous) were derived from the following equation, which is based on the conservation of mass.

$$
\mathrm{V} \times \frac{\mathrm{dCi}}{\mathrm{dt}}=\mathrm{R} \times \mathrm{E}_{\mathrm{f}}-\mathrm{Q} \times \mathrm{Ci}
$$

where $\mathrm{V}\left(\mathrm{m}^{3}\right)$ is the volume of the test chamber; $\mathrm{C}_{i}\left(\mathrm{mg} / \mathrm{m}^{3}\right.$ or particles $\left./ \mathrm{cm}^{3}\right)$ is the concentration of gas or particles at a given time; $\mathrm{R}(\mathrm{g} / \mathrm{hr})$ is the incense-burning rate; $\mathrm{E}_{\mathrm{f}}(\mathrm{mg} / \mathrm{g}$ or particles/g) is the emission factor of each pollutant, and $\mathrm{Q}(5$ $\mathrm{L} / \mathrm{min}$ ) is the air flow rate. $\mathrm{dCi} / \mathrm{dt}=0$ when generation and removal are in dynamic equilibrium. Equation 1 is then rewritten as follows.

$$
\mathrm{E}_{\mathrm{f}}=\frac{\mathrm{Q} \times \mathrm{C}}{\mathrm{R}}
$$

In Eq. 2, the emission rate is defined as: $\mathrm{Q} \times \mathrm{C}$, which is the flow rate multiplied by the equilibrium concentration of the pollutant. Then, the emission factor, $\mathrm{E}_{\mathrm{f}}$, can be thought of as the specific emission rate normalized to the incense burning rate. The expression for the concentrations of gaseous pollutants was converted from $\mathrm{ppm}\left(\mathrm{v} / \mathrm{v}\right.$ at $25^{\circ} \mathrm{C}, 1 \mathrm{~atm}$.) to $\mathrm{mg} / \mathrm{m}^{3}$ based on the ideal gas law. In this conversion, the molecular weight of the total VOCs was set to $92 \mathrm{~g}$, as a toluene equivalent. 


\section{RESULTS AND DISCUSSION}

The heating value of the incense was $5060 \mathrm{Kcal} / \mathrm{Kg}$. The weight percentages of carbon, hydrogen, nitrogen, ash and water in the incense were $61.96,2.62,0.70$, 12.28 and $5.86 \%$, respectively. The burning tips of an incense cone with heights from 13.5 to $25 \mathrm{~mm}$ varied as the diameter increased. Along with the increment of diameter, the average surface temperature at the burning tip changed from 368.0 ${ }^{\circ} \mathrm{C}(\mathrm{n}=3, \mathrm{CV}=0.02), 395.8^{\circ} \mathrm{C}(\mathrm{n}=3, \mathrm{CV}=0.04)$ to $450.1^{\circ} \mathrm{C}(\mathrm{n}=3, \mathrm{CV}=0.04)$. Additionally, the burning rate increased from $1.67 \mathrm{~g} / \mathrm{hr}(\mathrm{n}=3, \mathrm{CV}=0.02), 2.19 \mathrm{~g} / \mathrm{hr}$ $(\mathrm{n}=3, \mathrm{CV}=0.06)$ to $3.3 \mathrm{~g} / \mathrm{hr}(\mathrm{n}=3, \mathrm{CV}=0.07)$ (Fig. 1). The burning tip appeared brighter as the diameter increased from $3 \mathrm{~mm}$ to $5 \mathrm{~mm}$. Since the surface areas of the incense burning tips increased with diameters, oxygen became more available to the surface of the burning tip, promoting the combustion of char as well as the release heat. Therefore, the heat increased both the incense burning rate and the surface temperature of the incense burning tip.

Figure 2 plots the size distribution of particulates from burning the three incenses at a flow rate of $5 \mathrm{~L} / \mathrm{min}$. The number concentrations of particles of size 88.2 914 $\mathrm{nm}$ increased with diameter of the incense as the particles were grouped by size in increments of $0.7 \mathrm{~nm}\left(\mathrm{n}=6, \mathrm{~F}=2.74 \sim 7.37, \mathrm{~F}_{0.1}(2,15)=2.7\right)$. However, the number concentrations of particles of size $18.1 \sim 88.2 \mathrm{~nm}$ did not differ significantly with diameter of incense $\left(n=6, F=0.17 \sim 2.3, F_{0.1}(2,15)=2.7\right)$. The sizes of particulates from burning incense tend increase as the diameter of the incense increases. The yield of low volatile vapors and particulates at the beginning of incense burning likely depends on the incense diameter. Incense with a large diameter seems to produce a larger quantity of low-volatile organic compounds as well as particles than one with a smaller diameter. The low volatile materials might condense or adsorb on the surface of primary combustion particles. Moreover, the coagulation of primary combustion particles may ultimately increase the particle size.

In fact, the Fig. 3 shows that the particle concentration (number, volume or mass) increased linearly with the diameter of the incense. The emission rate, which is the product of the concentration and the air flow rate of $5 \mathrm{~L} / \mathrm{min}$, varied similarly.

However, the emission factor was correlated inversely with the incense diameter. The particle number emission rates and factors from smoldering incenses with various incense diameters ranged from $3.85 \times 10^{12} \mathrm{~A} / \mathrm{hr}(\mathrm{n}=6, \mathrm{CV}=0.02)$ to $4.32 \times$ $10^{12} \# / \mathrm{hr}(\mathrm{n}=6, \mathrm{CV}=0.01)$ and from $2.28 \times 10^{12} \# / \mathrm{g}(\mathrm{n}=6, \mathrm{CV}=0.03)$ to $1.36 \times 10^{12}$ $\# / g(n=6, C V=0.02)$, respectively. The volume emission rates and factors ranged from $5.05 \times 10^{18} \mathrm{~nm}^{3} / \mathrm{hr}(\mathrm{n}=6, \mathrm{CV}=0.03)$ to $6.97 \times 10^{18} \mathrm{~nm}^{3} / \mathrm{hr}(\mathrm{n}=6, \mathrm{CV}=0.04)$ and $2.99 \times 10^{18} \mathrm{~nm}^{3} / \mathrm{g}(\mathrm{n}=6, \mathrm{CV}=0.06)$ to $2.19 \times 10^{18} \mathrm{~nm}^{3} / \mathrm{g}(\mathrm{n}=6, \mathrm{CV}=0.06)$, respectively. The mass emission rates and factors ranged from $8.6 \mathrm{mg} / \mathrm{hr}(\mathrm{n}=3, \mathrm{CV}=0.04)$ to 9.2 $\mathrm{mg} / \mathrm{hr}(\mathrm{n}=3, \mathrm{CV}=0.04)$ and from $5.1 \mathrm{mg} / \mathrm{g}(\mathrm{n}=3, \mathrm{CV}=0.04)$ to $2.9 \mathrm{mg} / \mathrm{g}(\mathrm{n}=3$, $\mathrm{CV}=0.04)$, respectively. These mass emission rates and factors differed from those determined by Lee et al. Lee et al. (2004) they characterized the emissions from traditional incenses in a large environmental chamber. The emission rates of 

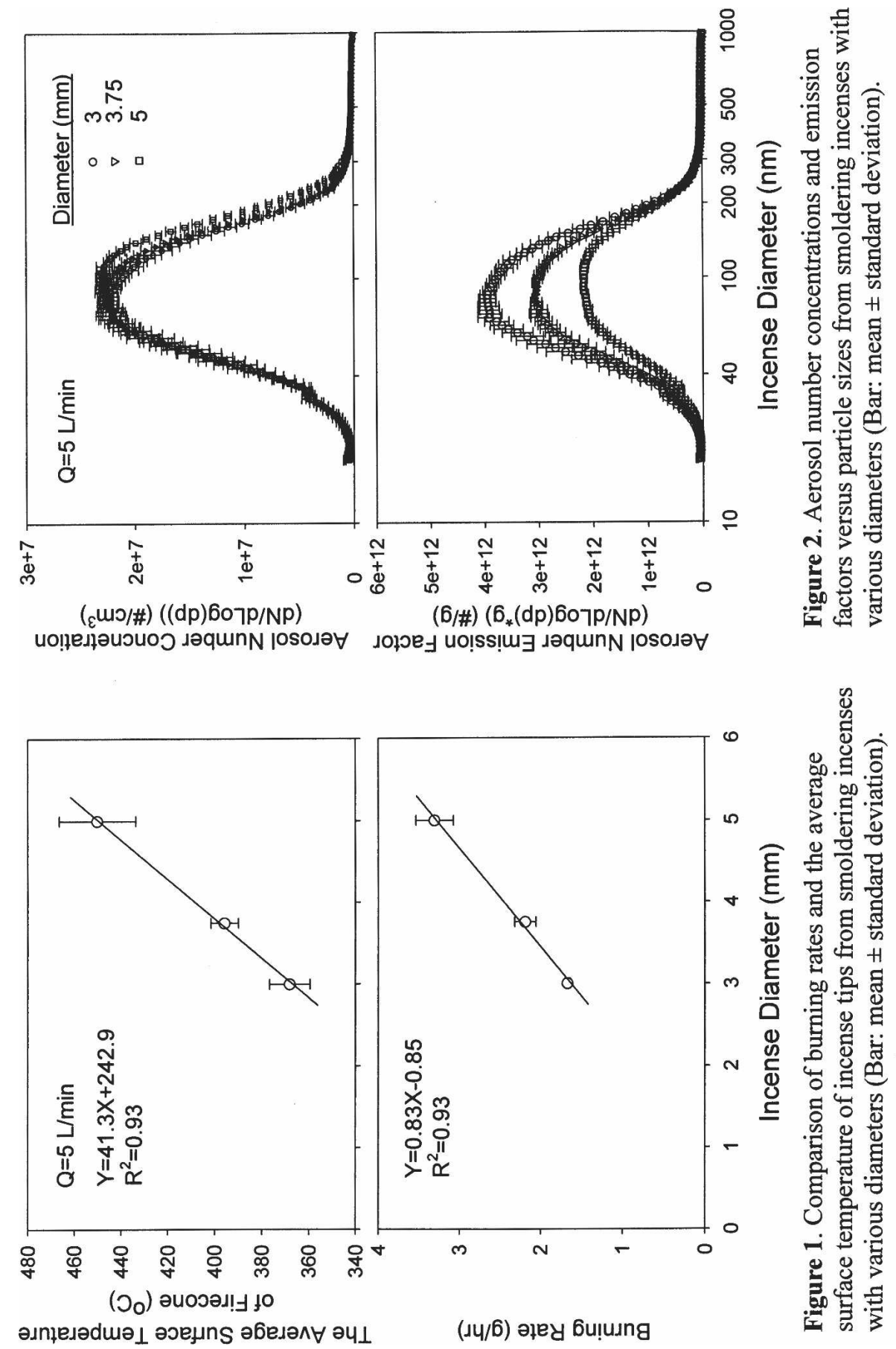


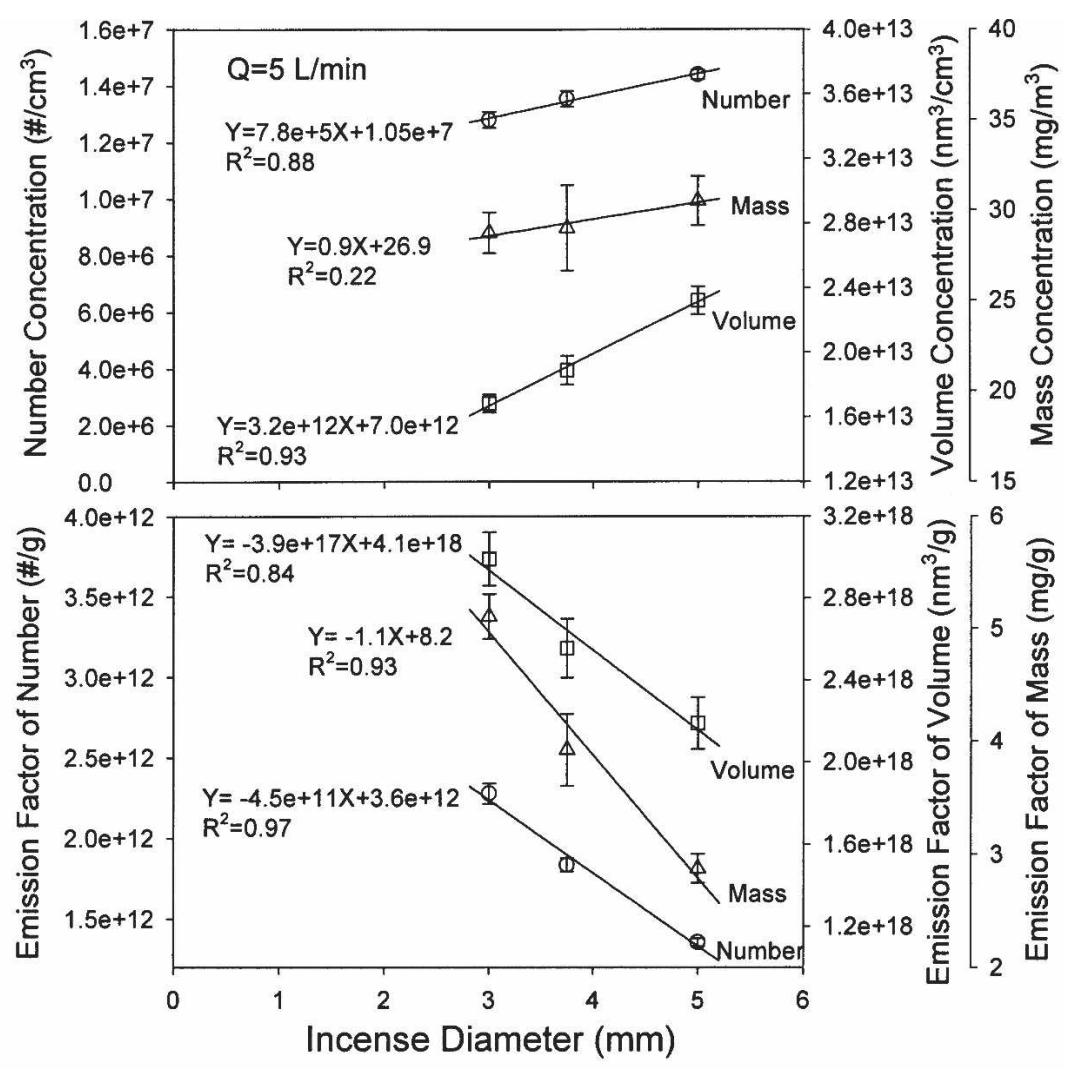

Figure 3. Comparison of aerosol numbers, volume, mass concentrations, and emission factors from smoldering incenses with various diameters (Bar: mean \pm standard deviation).

PM2.5 were $28.4 \sim 372.6 \mathrm{mg} / \mathrm{hr}$, and the emission factor was $104 \sim 9.6 \mathrm{mg} / \mathrm{g}$. The results probably differed from those herein because each study used different incense and combustion conditions.

The concentrations of $\mathrm{CO}_{2}, \mathrm{CO}$ and TVOCs, and their emission rate consistently increased with temperature from 368.0 to $450.1^{\circ} \mathrm{C}$ as incense of various diameters was burned (Fig. 4). The linear regression models for the emission rates of $\mathrm{CO}_{2}, \mathrm{CO}$ and TVOCs versus incense diameter were $\mathrm{y}=1003.8 \mathrm{x}-682.1$ $\left(R^{2}=1.00\right), y=414.2 x-385.8\left(R^{2}=1.00\right)$ and $y=58.0 x-50.1\left(R^{2}=0.98\right)$, respectively. The $\mathrm{CO}_{2}$ emission rates of incense ranged from $2322.0 \mathrm{mg} / \mathrm{hr}(\mathrm{n}=3$, $\mathrm{CV}=0.03)$ to $4332.6 \mathrm{mg} / \mathrm{hr}(\mathrm{n}=3, \mathrm{CV}=0.01)$. The $\mathrm{CO}$ emission rates were from $845.9 \mathrm{mg} / \mathrm{hr}(\mathrm{n}=3, \mathrm{CV}=0.02)$ to $1684.0 \mathrm{mg} / \mathrm{hr}(\mathrm{n}=3, \mathrm{CV}=0.002)$. The TVOCs emission rates ranged from $13.0 \mathrm{mg} / \mathrm{hr}(\mathrm{n}=3, \mathrm{CV}=0.05)$ to $24.4 \mathrm{mg} / \mathrm{hr}(\mathrm{n}=3$, $\mathrm{CV}=0.02$ ). However, the emission factors of $\mathrm{CO}_{2}, \mathrm{CO}$ or TVOCs were not significantly correlated with incense diameter. The $\mathrm{CO}_{2}$ emission factors of the 


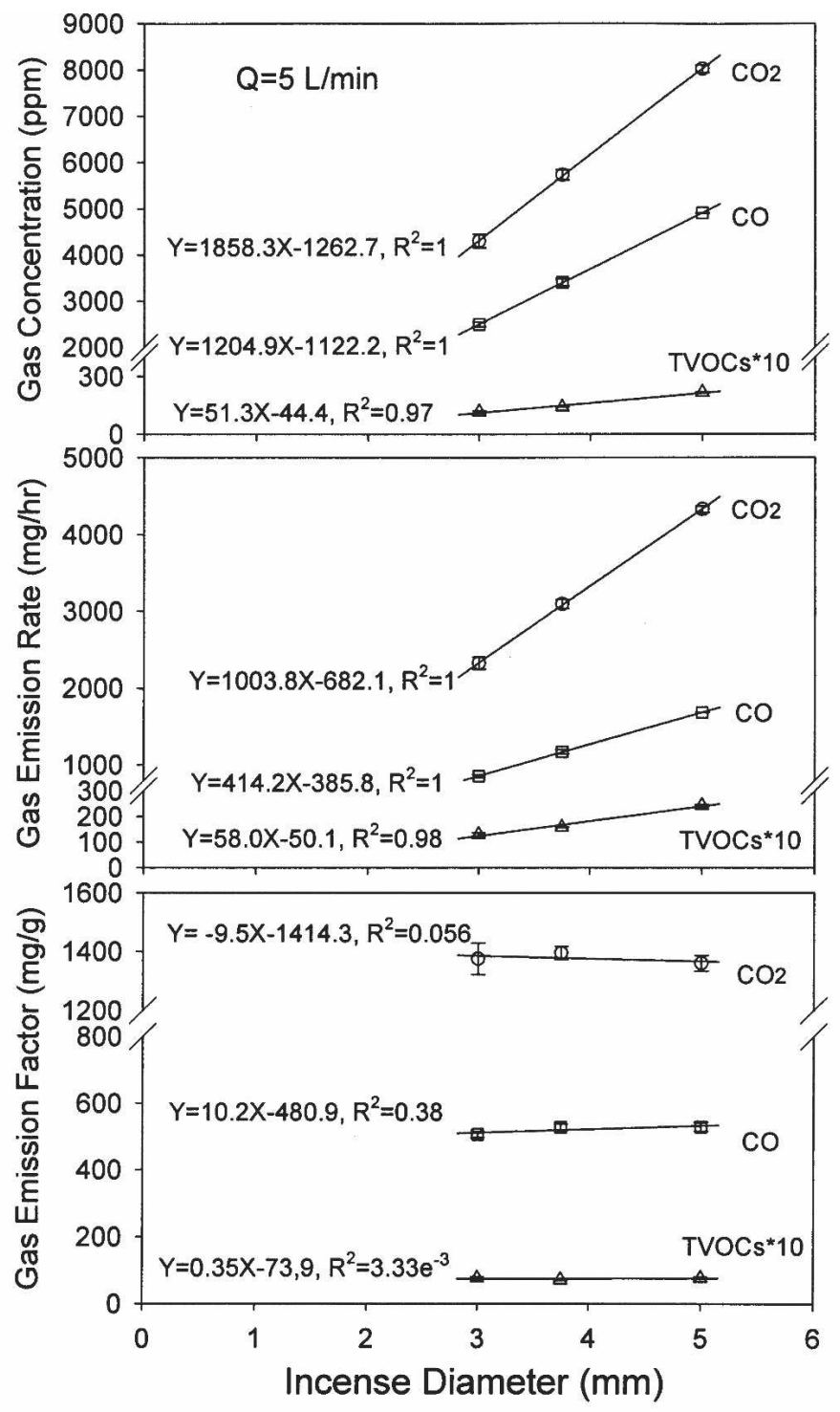

Figure 4. Comparison of $\mathrm{CO}_{2}, \mathrm{CO}$, and TVOCs emission concentrations and corresponding emission factors from smoldering incenses with various diameters (Bar: mean \pm standard deviation).

incenses ranged from $1360.6 \mathrm{mg} / \mathrm{g}(\mathrm{n}=3, \mathrm{CV}=0.02)$ to $1375.5 \mathrm{mg} / \mathrm{g}(\mathrm{n}=3$, $\mathrm{CV}=0.04)$. The range of $\mathrm{CO}$ emission factors was $506.3 \mathrm{mg} / \mathrm{g}(\mathrm{n}=3, \mathrm{CV}=0.02)$ to $528.9 \mathrm{mg} / \mathrm{g}(\mathrm{n}=3, \mathrm{CV}=0.02)$. The range of TVOCs emission factors was from 7.1 $\mathrm{mg} / \mathrm{g}(\mathrm{n}=3, \mathrm{CV}=0.06)$ to $7.7 \mathrm{mg} / \mathrm{g}(\mathrm{n}=3, \mathrm{CV}=0.04)$.

However, the combustion efficiency $\left(\left(\mathrm{CO}_{2}\right) /\left(\mathrm{CO}+\mathrm{CO}_{2}\right)\right)$, based on the $\mathrm{CO}$ and 


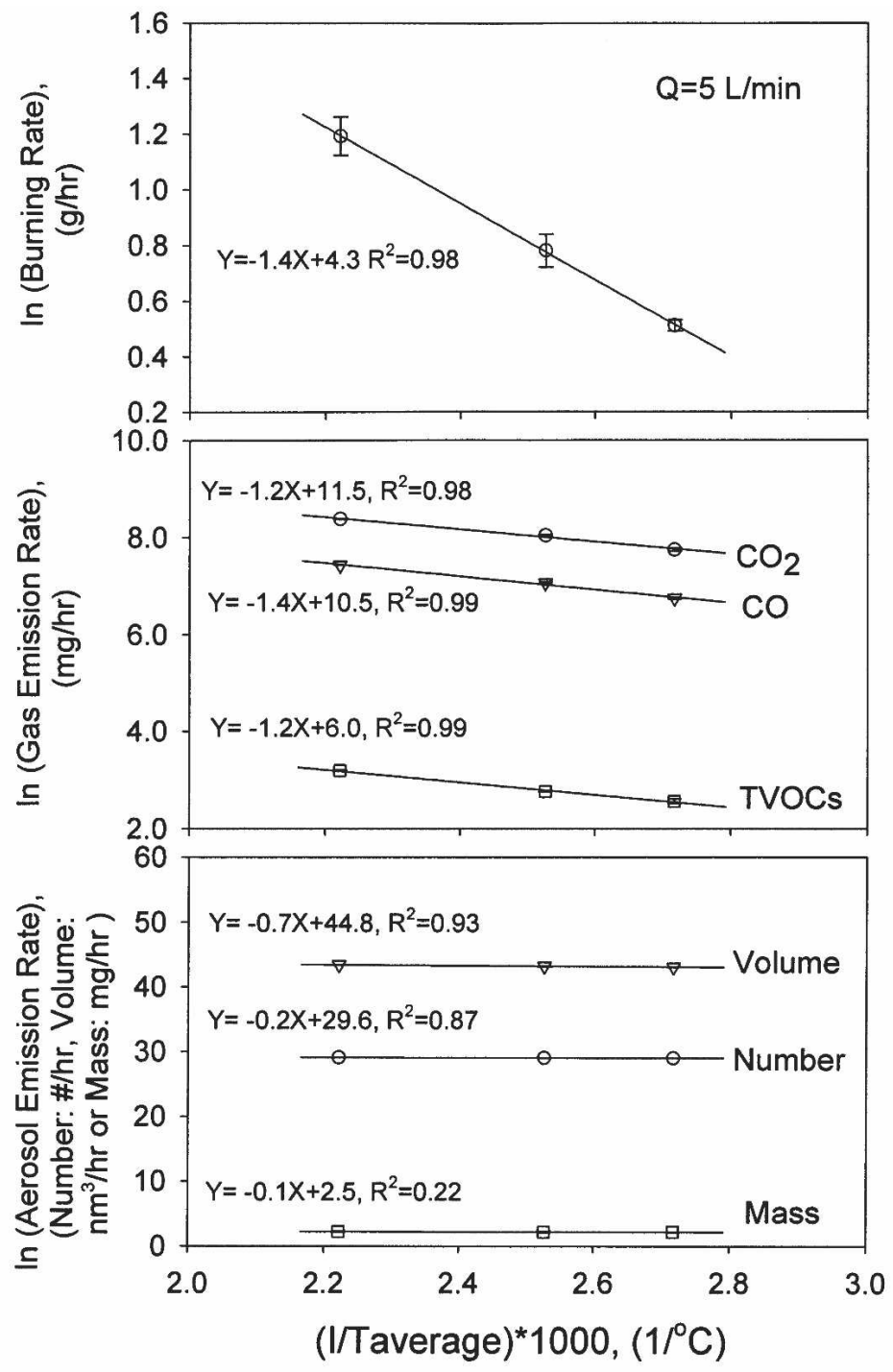

Figure 5. The plots of incense burning rate, gas, and particle emission rates versus $\left(1 / \mathrm{T}_{\text {average }}\right) * 1000$ from smoldering incenses (Bar: mean \pm standard deviation).

$\mathrm{CO}_{2}$ concentrations, ranged from $0.63(\mathrm{n}=3, \mathrm{CV}=0.007)$ to $0.62(\mathrm{n}=3, \mathrm{CV}=0.003)$, and was negative correlating with incense diameter $\left(y=-6.19 x+0.65, R^{2}=0.80\right)$, indicating that combustion was relatively incomplete in the smoldering of coarse incenses.

The Arrhenius plot presented in Fig. 5 demonstrates that the emission rate of $\mathrm{CO}_{2}$, $\mathrm{CO}$, TVOCs or particles is mainly associated with the temperature, which depends 
on the diameter of the incense. Thus, the smoldering incense at the lowest burning tip temperature produced the least amount of gaseous and particulate pollutants.

Acknowledgments. The authors would like to thank the National Science Council of the Republic of China, Taiwan, for financially supporting this research under Contract No. NSC-92-2320-B-002-157.

\section{REFERENCES}

Chang HL, Kuo ML, Lee JK (1997) Mutagenic activity of incense smoke in comparison to formaldehyde and acetaldehyde in Salmonella typhimurium TA102. Bull Environ Contam Toxicol 58:394-401.

Cheng YS, Bechtold WE, Yu CC, Hung IF (1995) Incense smoke: Characterization and dynamics in indoor environments. Aerosol Sci Technol 23:271-981.

Dick CA, Brown DM, Donaldson K (2003) The role of free radicals in the toxic and inflammatory effects of four different ultrafine particle types. Inhal Toxicol 15:39-52.

Jetter JJ, Guo Z, Mcbrian JA, Flynn MR (2002) Characterization of emissions from burning incense. Sci Tot Environ 295:51-67.

Lee SC, Wang B (2004) Characteristics of incense of air pollutants from burning of incense in a large environmental chamber. Atmos Environ 38:941-951.

Lin JM, Lee JK (1998) Vaporous and particulate-bound polycyclic aromatic hydrocarbons in Chinese incense smoke. Toxicol Environ Chem 67:105-113.

Lin JM, Tang CS (1994) Characterization and aldehyde content of particulates in Chinese incense smoke. Bull Environ Contam Toxicol 53:895-901.

Lin JM, Wang LH (1994) Gaseous aliphatic aldehydes in Chinese incense smoke. Bull Environ Contam Toxicol 53:374-481.

Lowengard RA, Peters JM, Cinioni C, Buckley J, Bernstein L, Preston-Martin S, Edward R (1987) Childhood leukemia and parent's occupation and home exposure. J Natl Cancer Inst 79(1):39-46.

Maclennan R, Costa JD, Day NE, Law CH, Ng YK, Shanmugaratnam K (1977) Risk factors for lung cancer in Singapore Chinese, A population with high female incidence rate. Int J Cancer 20:854-860.

Preston-Martin S, Yu MC, Benten B, Henderson BE (1982) N-nitroso compounds and childhood brain tumors: A case-control study. Cancer Res 42:5240-5245.

Rasmussen RE (1987) Mutagenic activity of incense smoke in Salmonella typhimurium. Bull Environ Contam Toxicol 38:827-833.

Sato S, Makino R, Takahashi Y, Sugimura T, Miyazaki T (1980) Mutagenicity of smoke condensates from joss sticks. Mut Res 77:31-36.

Schoental R, Gibbard S (1967) Carcinogens in Chinese incense smoke. Nature 216:612.

Yang TT, Chen CC, Lin JM (2005) Effect of air flow on emission of smoldering incense. Bull Environ Contam Toxicol 74:456-463. 